\title{
Wavelength-Division Demultiplexing Using Photonic Crystal Waveguides
}

Niemi, Tapio; Frandsen, Lars Hagedorn; Hede, Kristian Knak; Harpøth, Anders; Borel, Peter Ingo; Kristensen, Martin

Published in:

I E E E Photonics Technology Letters

Link to article, DOI:

10.1109/LPT.2005.860001

Publication date:

2005

Document Version

Publisher's PDF, also known as Version of record

Link back to DTU Orbit

Citation (APA):

Niemi, T., Frandsen, L. H., Hede, K. K., Harpøth, A., Borel, P. I., \& Kristensen, M. (2005). Wavelength-Division Demultiplexing Using Photonic Crystal Waveguides. I E EE Photonics Technology Letters, 18(1), 226-228. https://doi.org/10.1109/LPT.2005.860001

\section{General rights}

Copyright and moral rights for the publications made accessible in the public portal are retained by the authors and/or other copyright owners and it is a condition of accessing publications that users recognise and abide by the legal requirements associated with these rights.

- Users may download and print one copy of any publication from the public portal for the purpose of private study or research.

- You may not further distribute the material or use it for any profit-making activity or commercial gain

- You may freely distribute the URL identifying the publication in the public portal

If you believe that this document breaches copyright please contact us providing details, and we will remove access to the work immediately and investigate your claim 


\title{
Wavelength-Division Demultiplexing Using Photonic Crystal Waveguides
}

\author{
Tapio Niemi, Lars Hagedorn Frandsen, Kristian Knak Hede, Anders Harpøth, Peter Ingo Borel, and Martin Kristensen
}

\begin{abstract}
We demonstrate a new device concept for wavelength division demultiplexing based on planar photonic crystal waveguides. The filtering of wavelength channels is realized by shifting the cutoff frequency of the fundamental photonic bandgap mode in consecutive sections of the waveguide. The shift is realized by modifying the size of the border holes. Simulations and an experimental realization of a four-channel coarse wavelength division demultiplexer are described.
\end{abstract}

Index Terms-Photonic bandgap (PBG), photonic crystal (PhC) waveguide, wavelength-division multiplexing (WDM).

\section{INTRODUCTION}

$\mathbf{P}$ HOTONIC crystal structures are considered promising building blocks for use in integrated nanophotonic circuits. Some of the most successful structures are based on planar photonic crystals (PhCs). In such waveguides, the optical field is confined, horizontally, by a photonic bandgap (PBG) provided by the $\mathrm{PhC}$ and, vertically, by total internal reflection due to refractive index differences. Various $\mathrm{PhC}$ components, such as waveguides, bends, Y splitters, and directional couplers, have already been realized [1]-[9]. These basic building blocks can be combined to realize complete circuits with various optical functions within an extremely small area.

One of the most important fields for ultra-dense integrated circuits is optical communications. A key component in modern optical communications systems is a wavelength division multiplexer (WDM). This component is needed to divide and combine different wavelength channels each carrying an optical data signal. Traditionally, WDM components are realized using thin-film filters, fiber Bragg gratings (FBG), or arrayed waveguide gratings. However, such devices are not convenient for ultra-dense integration. Various concepts for realizing a WDM component utilizing the extraordinary properties of PhCs have recently been proposed. These ideas include optical microcavities, directional couplers, multimode self-imaging waveguides, and superprisms [10]-[15].

\footnotetext{
Manuscript received May 10, 2005; revised September 1, 2005. This work was supported by the Danish Technical Research Council under the Planar Integrated PBG Elements (PIPE) Programs. The work of T. Niemi was supported by GETA, NorFa, and the Emil Aaltonen Foundation.

T. Niemi was with the Research Center COM, Technical University of Denmark, 2800 Kgs. Lyngby, Denmark. He is now with the Optoelectronics Research Centre, Tampere University of Technology, Tampere, Finland (e-mail: Tapio.k.Niemi@tut.fi).

L. H. Frandsen, K. K. Hede, A. Harpøth, and P. I. Borel are with the Research Center COM, Technical University of Denmark, 2800 Kgs. Lyngby, Denmark.

M. Kristensen was with the Research Center COM, Technical University of Denmark, $2800 \mathrm{Kgs}$. Lyngby, Denmark. He is now with the Department of Physics and Astronomy and Interdisciplanary Nanoscience Center (iNANO), University of Aarhus, DK-8000 Århus C, Denmark.

Digital Object Identifier 10.1109/LPT.2005.860001
}

In this letter, we report on a novel concept for a wavelength demultiplexer. Its operation principle is based on a shift of the cutoff frequency of the fundamental PBG mode in a planar photonic crystal waveguide ( $\mathrm{PhCW})$. The shift is realized by varying the size of the border holes adjacent to the waveguide core. We present numerical simulations to describe the operation principle of the WDM component and show experimental results from a four-channel demultiplexer fabricated in a silicon-on-insulator (SOI) material. We believe that this device concept leads the way to a practical realization of $\mathrm{PhC}$ components for WDM.

\section{OPERATION PRINCIPLE}

The operation principle and properties of the proposed multiplexer are described by utilizing numerical modeling in two dimensions. However, the extension of the basic principles to real three-dimensional (3-D) structures is straightforward. The $\mathrm{PhC}$ is defined in the top silicon (epi-) layer of an SOI material by arranging holes in a triangular arrangement. A so-called W1 $\mathrm{PhCW}$ is formed by removing one row of holes in the nearest neighbor direction of the PhC. The properties of the guided $\mathrm{PhCW}$ modes, their dispersion, and their cutoff frequencies can be obtained from the dispersion relation of the waveguide. The dispersion curves of the waveguide can be calculated by using a freely available software package, e.g., [16]. The photonic bandgap of the horizontal crystal structure supports TE-polarized waveguide modes (i.e., the magnetic field is parallel to the air holes). The fundamental PBG mode has an even symmetry with respect to center of the waveguide and the first-order mode has an odd symmetry. Usually, only the fundamental even mode is excited in the PhCW due to a large overlap with the fundamental mode of a ridge waveguide, which is often used to route light from the sample facet to the $\mathrm{PhCW}$ and vice versa. The propagation properties of the guided modes can be modified by altering the holes adjacent to the waveguide core. By changing the diameter of the border holes the cutoff frequency of the guided mode can be shifted either up or down in frequency [17]-[19]. Specifically, by increasing the size of the border holes the cutoff frequency can be shifted to higher frequencies.

A demonstration of how the dispersion relation of the fundamental PBG mode can be modified is shown in Fig. 1. In this example, the background material is silicon $(n=3.476)$ and the diameter of the $\mathrm{PhC}$ air holes $d=0.60 \Lambda$ where $\Lambda$ is the lattice pitch. The dispersion relation for the fundamental PBG mode is shown for diameters of the border holes D $0.60,70,75$, 80 , and $0.85 \Lambda$.

As the diameter of the border holes is increased, the edge of the transmission band shifts to shorter wavelengths. 


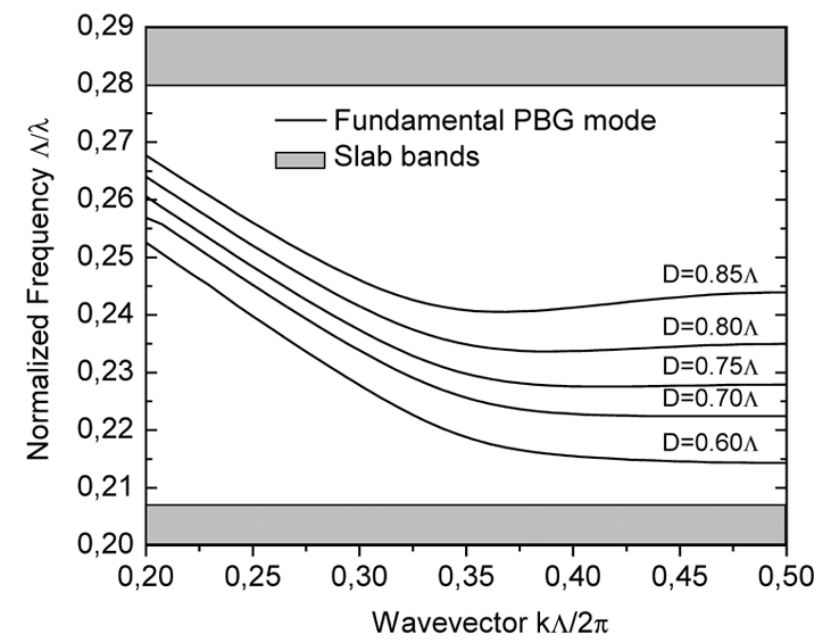

Fig. 1. Shift of cutoff frequency of fundamental photonic bandgap mode for different diameters of border holes.

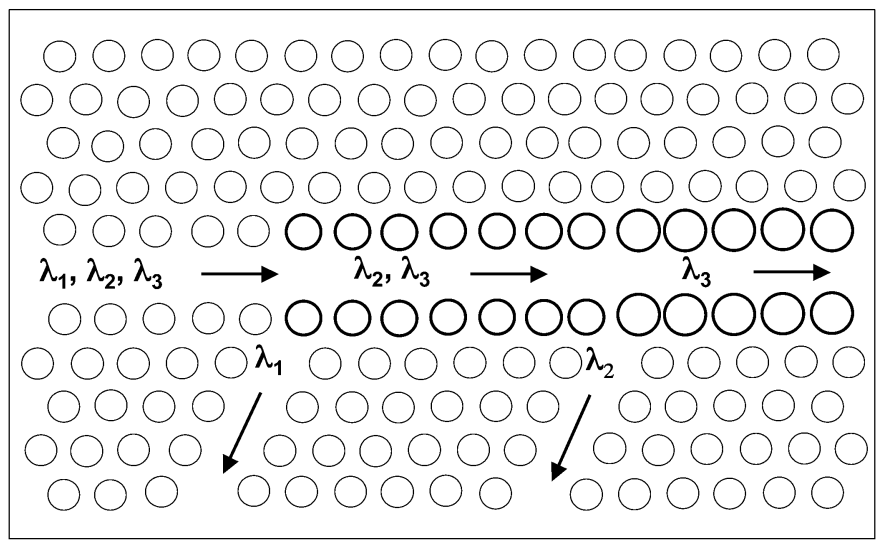

Fig. 2. Scheme of two-channel demultiplexer realized using a planar photonic crystal waveguide with consecutive sections of large border holes. With this configuration, wavelengths are demultiplexed in order $\lambda_{1}>\lambda_{2}>\lambda_{3}$.

By enlarging the size of the border holes in consecutive sections along the $\mathrm{PhCW}$, this effect can be used to successively block a narrow wavelength band near the low-frequency transmission edge for being transmitted. The blocked part of the transmission band can be collected and guided in a closely and appropriately placed waveguide. In effect, a wavelength channel is demultiplexed to the adjacent $\mathrm{PhCW}$ from the incident signal. Therefore, a PhCW having consecutive sections with modified border holes can be applied as a multichannel optical demultiplexer. The scheme and the operation principle of a two-channel demultiplexer are displayed in Fig. 2.

\section{FABRicATION OF DEMULTIPLEXER}

We have fabricated a PhC four-channel WDM component, which experimentally verifies the demultiplexing principle described in the previous section. We use planar PhCWs defined in the top 340-nm-thick silicon layer of an SOI-wafer having a $1-\mu \mathrm{m}$-thick silica buffer layer. The pattern defining the $\mathrm{PhC}$ structures was realized in a spun-on resist by utilizing electron beam lithography. Subsequently, the pattern was transferred to the silicon layer by reactive-ion etching. The bulk $\mathrm{PhC}$ structure has a pitch $\Lambda=380 \mathrm{~nm}$ and the diameter of the holes is $d \approx 260 \mathrm{~nm}$. The holes are etched only through the

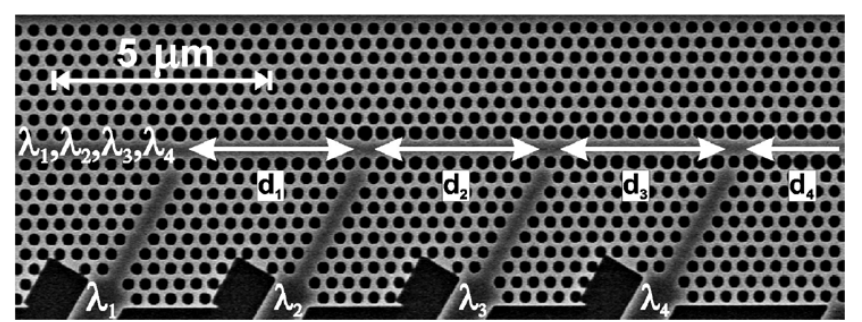

Fig. 3. SEM of fabricated four-channel demultiplexer with different border hole diameters $d$ in consecutive sections. $d_{4}>d_{3}>d_{2}>d_{1}$ and dropping of wavelengths will occur in order $\lambda_{1}>\lambda_{2}>\lambda_{3}>\lambda_{4}$. Length of each of waveguide sections $d_{1-4}$ is $10 \Lambda$.

top silicon layer. The cutoff frequency of the guided PBG mode of the waveguide was modified by changing the size of the border holes. The diameter of the holes was designed to gradually increase in steps of $20 \mathrm{~nm}$ between consecutive sections with lengths of $10 \Lambda$. Four sections were fabricated having the nominal diameters of the border holes of 290, 310, 330 , and $350 \mathrm{~nm}$. A scanning electron micrograph (SEM) of the fabricated component is displayed in Fig. 3. The figure shows the input $\mathrm{PhCW}$ and the four drop channels of the component. Light is routed to the WDM component from the sample facet using a tapered ridge waveguide with a total length of $\sim 4 \mathrm{~mm}$. The ridge waveguide is tapered from $4 \mu \mathrm{m}$ at the facets of the SOI-wafer to $1 \mu \mathrm{m}$ at the $\mathrm{PhCW}$ interface. The width of $1 \mu \mathrm{m}$ of the ridge waveguide ensures a nice overlap between the fundamental mode of the ridge waveguide and the fundamental PBG mode of the PhCW and, hence, decreases the coupling loss to the $\mathrm{PhCW}$. The output of the four drop channels are connected to ridge waveguides, which are bent smoothly with a radius of $\sim 40 \mu \mathrm{m}$ to have their exit ports aligned parallel to the direct transmitted channel of the WDM component. This configuration simplifies the optical characterization of the component.

\section{MEASUREMENTS}

The components were characterized by using two broad-band light-emitting diodes (LEDs) as sources to cover the wavelength range $\sim 1250-1550 \mathrm{~nm}$. Tapered-lensed fibers were used to couple light into the ridge waveguides connected to the demultiplexer component. Two polarization controllers and a polarizer crystal were applied to obtain the TE-polarization of the waveguides. The output from each of the channels was recorded with an optical spectrum analyzer using a resolution bandwidth of $10 \mathrm{~nm}$. The recorded spectra were normalized to the transmission of a tapered ridge waveguide with a length of $\sim 4 \mathrm{~mm}$. The measured spectra for each of the demultiplexed channels are displayed in Fig. 4. The different drop channels peak around $1345,1385,1405$, and $1440 \mathrm{~nm}$ for the channels $\lambda_{1}, \lambda_{2}, \lambda_{3}$, and $\lambda_{4}$, respectively. The difference in transmission level between the channels is primarily due to propagation losses in the PhCW sections.

\section{DISCUSSION}

We have proposed a novel device concept for an integrated optical demultiplexer based on planar photonic crystal structures. Measured spectra on a fabricated component show an ex- 


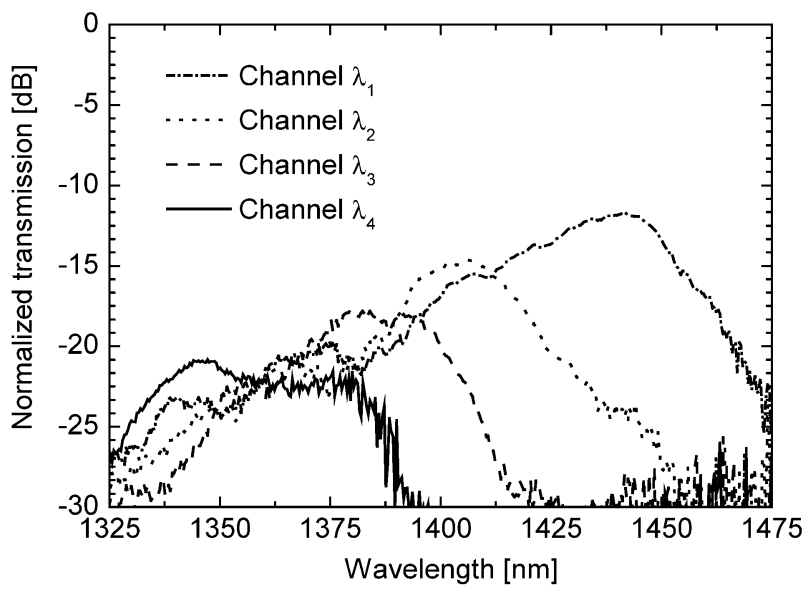

Fig. 4. Demultiplexed wavelength channels from fabricated component. Spectra have been normalized to transmission through tapered ridge waveguide.

perimental verification of the operational principle. However, the width of each dropped wavelength channel, loss, crosstalk, and the varying channel spacing calls for further improvement and optimization before this component can be utilized in practical applications. The loss of the component is most likely a result of coupling to the silica layer since the operation range of the waveguides is close to the light line. Some additional loss may be due to coupling of TE-like modes to TM-like slab modes resulting from the asymmetric SOI structure [20], [21].

The operation of the component is based on shifting the longwavelength edge of the transmission band of the TE-like even mode of the waveguide. The shift of the edge is very sensitive to perturbations of the border holes adjacent to the waveguide core. The wavelength shift related to the diameter of the border holes is $\sim 2 \mathrm{~nm} / \mathrm{nm}$ in our device. Wavelengths falling outside the transmission band cannot propagate in the waveguide but form an evanescent wave. Hence, the main part of the light is reflected back. The key issue in the operation of the proposed demultiplexer is to collect the signal to the drop channels. In the present configuration, the intersections between two waveguides with different border hole diameters were slightly optimized by applying a large hole opposite to the drop channel (see Fig. 3). However, further modeling is needed to understand and optimize the complex coupling mechanism, which also includes evanescent waves and resonance effects. One promising method for designing optimized photonic crystal structures in a systematic way is topology optimization [5], which could be utilized to improve the general characteristics of the component.

In conclusion, we have demonstrated a novel component for wavelength demultiplexing based on photonic crystal waveguides. This device leads the way to achieve the CWDM channel spacing of $20 \mathrm{~nm}$ defined by ITU-T Recommendation G.694.2. We believe that this component is one of the first experimental demonstrations of doing in-plane multichannel filtering and demultiplexing.

\section{REFERENCES}

[1] S. J. McNab, N. Moll, and Y. A. Vlasov, "Ultra-low loss photonic integrated circuit with membrane-type photonic crystal waveguides," Opt. Expr., vol. 11, pp. 2927-2939, 2003.

[2] Y. Sugimoto, Y. Tanaka, N. Ikeda, Y. Nakamura, K. Asakawa, and K. Inoue, "Low propagation loss of $0.76 \mathrm{~dB} / \mathrm{mm}$ in GaAs-based single-linedefect two-dimensional photonic crystal slab waveguides up to $1 \mathrm{~cm}$ in length," Opt. Expr., vol. 12, pp. 1090-1096, 2004.

[3] E. Chow, S. Y. Lin, J. R. Wendt, S. G. Johnson, and J. D. Joannopoulos, "Quantitative analysis of bending efficiency in photonic-crystal waveguide bends at $\lambda=1.55 \mu \mathrm{m}$ wavelengths," Opt. Lett., vol. 26, pp. 286-288, 2001.

[4] M. Tokushima, H. Kosaka, A. Tomita, and H. Yamada, "Lightwave propagation through a $120^{\circ}$ sharply bent single-line-defect photonic crystal waveguide," Appl. Phys. Lett., vol. 76, pp. 952-954, 2000.

[5] P. I. Borel, A. Harpøth, L. H. Frandsen, M. Kristensen, P. Shi, J. S. Jensen, and O. Sigmund, "Topology optimization and fabrication of photonic crystal structures," Opt. Expr., vol. 12, pp. 1996-2001, 2004.

[6] L. H. Frandsen, A. Harpøth, P. I. Borel, M. Kristensen, J. S. Jensen, and O. Sigmund, "Broadband photonic crystal waveguide $60^{\circ}$ bend obtained utilizing topology optimization," Opt. Expr., vol. 12, pp. 5916-5921, 2004.

[7] S. Y. Lin, E. Chow, J. Bur, S. G. Johnson, and J. D. Joannopoulos, "Low-loss, wide-angle Y splitter at approximately 1.6-um wavelengths built with a two-dimensional photonic crystal," Opt. Lett., vol. 27, pp. 1400-1402, 2000.

[8] L. H. Frandsen, P. I. Borel, Y. X. Zhuang, A. Harpøth, M. Thorhauge, M. Kristensen, W. Bogaerts, P. Dumon, R. Baets, V. Wiaux, J. Wouters, and S. Beckx, "Ultra-low-loss 3-dB photonic crystal waveguide splitter," Opt. Lett., vol. 29, pp. 1623-1625, 2004.

[9] M. Thorhauge, L. H. Frandsen, and P. I. Borel, "Efficient photonic crystal directional couplers," Opt. Lett., vol. 28, pp. 1525-1527, 2003.

[10] B.-S. Song, S. Noda, and T. Asano, "Photonic devices based on in-plane hetero photonic crystals," Science, vol. 300, p. 1537, 2003.

[11] M. Koshiba, "Wavelength division multiplexing and demultiplexing with photonic crystal waveguide couplers," J. Lightwave Technol., vol. 19, no. 5, pp. 1970-1975, May 2001.

[12] H. Kim, I. Park, B. O. S. Park, E. Lee, and S. Lee, "Self-imaging phenomena in multi-mode photonic crystal line-defect waveguides: Application to wavelength de-multiplexing," Opt. Expr., vol. 12, pp. $5625-5633,2004$

[13] F. S.-S. Chien, Y.-J. Hsu, W.-F. Hsieh, and S.-C. Cheng, "Dual wavelength demultiplexing by coupling and decoupling of photonic crystal waveguides," Opt. Expr., vol. 12, pp. 1119-1125, 2004.

[14] A. Sharkawy, S. Shi, and D. W. Prather, "Multichannel wavelength division multiplexing with photonic crystals," Appl. Opt., vol. 40, pp. 2247-2252, 2001.

[15] L. Wu, M. Mazilu, T. Karle, and T. F. Krauss, "Superprism phenomena in planar photonic crystals," IEEE J. Quantum Electron., vol. 38, no. 4, pp. 915-917, Apr. 2002.

[16] S. G. Johnson and J. D. Joannopoulos. (2001) Block-iterative frequencydomain methods for Maxwell's equations in a planewave basis. Optics Expr. [Online], pp. 173-190. Available: http://ab-initio.mit.edu/mpb/

[17] A. Adibi, R. K. Lee, Y. Xu, A. Yariv, and A. Scherer, "Design of photonic crystal optical waveguides with singlemode propagation in the photonic bandgap," Electron. Lett., vol. 36, pp. 1376-1378, 2000.

[18] M. Notomi, A. Shinya, K. Yamada, J. Takahashi, C. Takahashi, and I. Yokohama, "Structural tuning of guiding modes of line-defect waveguides of SOI photonic crystal slabs," IEEE J. Quantum Electron., vol. 38, no. 3, pp. 736-742, Mar. 2002.

[19] M. Notomi, A. Shinya, S. Mitsugi, E. Kuramochi, and H. Y. Ryu, "Waveguides, resonators and their coupled elements in photonic crystal slabs," Opt. Expr., vol. 12, pp. 1551-1561, 2004.

[20] Y. Tanaka, T. Asano, R. Hatsuta, and S. Noda, "Analysis of a line-defect waveguide on a silicon-on-insulator two-dimensional photonic-crystal slab," J. Lightwave Technol., vol. 22, no. 10, pp. 2787-2792, Oct. 2004.

[21] Y. Tanaka, T. Asano, Y. Akahane, B.-S. Song, and S. Noda, "Theoretical investigation of a two-dimensional photonic crystal slab with truncated cone air holes," Appl. Phys. Lett., vol. 82, pp. 1661-1663, 2003. 